\title{
Ciencia Socialmente Robusta: Algunas Reflexiones Epistemológicas
}

\author{
Alberto Cupani \\ Universidad Federal de Santa Catarina
}

\begin{abstract}
In Re-Thinking Science. Knowledge and the Public in an Age of Uncertainty (2001) H. Nowotny, P. Scott, e M. Gibbons vindicate a "socially robust" scientific knowledge in accordance with the social needs of our time. Such a knowledge would not be just epistemically reliable; in addition, it would also fit the situations to which will be put to use, and take into account the consequences of its utilization. In the authors' view, this new kind of science, which they call "Mode 2 knowledge" in another book, would do justice to a society that is not restrained to receive or ask for scientific information, but also requires sharing in its production. Nowotny and her colleagues mention several epistemological changes which a "robust" knowledge would involve. In this paper I analyze some of those alleged changes.
\end{abstract}

Keywords: Socially robust science; Mode 2 knowledge; Helga Nowotny; Peter Scott; Michael Gibbons.

\section{La reivindicación de un conocimiento científico "socialmente robusto"}

En Re-Thinking Science: Knowledge and the Public in an Age of Uncertainty (2001) H. Nowotny, P. Scott y M. Gibbons defienden la necesidad de un conocimiento científico "socialmente robusto" que corresponda a la diversas demandas sociales de nuestra época. Prolongando ideas expuestas en otra obra (The New Production of Knowledge, Gibbons et al. 1994), los autores llaman la atención sobre el cambio de la práctica científica de las últimas décadas, un cambio en dirección a una integración cada vez mayor de la ciencia y la tecnología en la solución de problemas económicos, políticos o sociales (paso al "modo 2 de conocimiento", diferente del "modo 1", el de la "ciencia académica"). En esta transformación, hasta la palabra ciencia va siendo substituida por la expresión "investigación" (research), una actividad que integra descubrimiento y fabricación. Las disciplinas y especialidades, aún no desapareciendo como hábitos académicos, son substituidas por equipos transitorios de investigadores constituidos para abordar problemas concretos.

Para Nowotny y sus colegas (en adelante Nowotny, por razones de comodidad) la comprensión de la nueva práctica científica exige reparar en que ella se procesa en un mundo en que la ciencia, la sociedad y la cultura "co-evolucionan", influyéndose recíprocamente como "arenas transgresivas" (o sea, que cada una de ellas "invade"

Principia 16(2): 319-340 (2012).

Published by NEL — Epistemology and Logic Research Group, Federal University of Santa Catarina (UFSC), Brazil. 
territorios antes propios de las otras, lo que resulta en una modificación de todas). ${ }^{1}$ Tratase de una situación de incertidumbre ubicua, para la que contribuyen tanto la pérdida de confianza en antiguos ideales y metas sociales (como la creencia en modos racionales universales de pensamiento y acción, o la eficacia de la planificación a largo plazo), como la constatación de que el avance científico, lejos de disminuir la incertidumbre, generalmente la aumenta. Vivimos, en gran parte por eso, en una "sociedad de riesgo" (Beck 2010) que, sin embargo, no puede dejar de ser una "sociedad de información", o sea, una vida social que exige, a cada momento, conocimientos confiables para las más diversas finalidades. Las demandas de conocimiento son dirigidas, obviamente, a la ciencia, cuyo valor social está, en principio, preservado por su manifiesta fecundidad tecnológica.

Y sin embargo, la ciencia ya no es lo que era (o se creía que era), no sólo por su metamorfosis en investigación utilitaria, sino también porque el aumento del valor práctico de la ciencia es acompañado por una disminución de su autoridad epistémica, y eso por diversas razones. No hay una única modalidad de investigación, no hay un único tipo de científico, y la manera de presentar lo que se deba entender por "Naturaleza" dejó de ser algo obvio. Sobre todo, de manera creciente las investigaciones deben conformarse a la situación-problema, y los investigadores precisan trabajar de forma interdisciplinaria. Más aún: deben combinar sus esfuerzos con los de los técnicos, con los de otros profesionales (médicos, administradores, abogados, designers ...) y hasta con los de los legos interesados o afectados por las producciones científico-tecnológicas o los cambios sociales posibilitados "científicamente". La investigación debe dar atención, no sólo al "contexto de aplicación" de los conocimientos, sino también al "contexto de implicación", esto es, a las consecuencias de las transformaciones proyectadas. El resultado de esos esfuerzos es, como no podía dejar de ser, un producto colectivo. ${ }^{2}$ Como si todo eso fuera poco, las informaciones y los diagnósticos científicos son a menudo criticados por los actores sociales en una dimensión antes no imaginada. ${ }^{3}$

En el corazón de ese cambio está otro, más importante para la filosofía de la ciencia. Paulatinamente, la ciencia ya no tiene u ocupa un especio social autónomo. Los científicos, es claro, continúan a reivindicar su autonomía, sea institucional, profesional o - especialmente - cognoscitiva (Nowotny 2001:160). Pero esa autonomía no está ya garantida, ni por el Estado, ni por el mercado, ni por la cultura (id.: 64). Como ya fue dicho, el científico pasa a ser, cada vez más, miembro de equipos heterogéneos, colaborando para la obtención de fines que generalmente tienen un carácter práctico. Las disciplinas científicas se volvieron "lugares de experimentación", lo que atenta contra su "estabilidad epistemológica", pues amenaza su pretensión de producir un acervo de verdades fundamentales sobre el mundo (id.: 188). A pesar de serios, esos cambios son menos graves que la pérdida de la autonomía cognoscitiva que, según nuestros autores, caracteriza la ciencia en este su "modo 2" de existencia.

Principia 16(2): 319-340 (2012). 
Eso significa que los criterios tradicionales de apreciación de las creencias científicas, así como las disposiciones que exigía la ciencia "académica" (el ethos de la ciencia, formulado por R. Merton) no son más los parámetros de la "buena ciencia". O mejor: no son ya los únicos parámetros de la ciencia respetada. Actualmente, la ciencia que importa socialmente debe incorporar otros criterios y exigencias. Para dar un ejemplo inmediato: el conocimiento científico, para ser confiable (reliable), no puede depender tan sólo del juicio de los pares (físicos, sociólogos, etc.), sino también de la opinión de los otros agentes envueltos en su producción, en su aplicación y hasta en sus consecuencias. Es precisamente esta ampliación de los indicios de confiabilidad que hará del conocimiento algo "robusto" (robust).

Sin embargo, se impone una distinción. Buena parte de las características identificadas en el "modo 2 " de conocimiento equivalen a lo que otros autores describen como "tecnociencia", o sea procesos de innovación fomentados por intereses económicos, políticos y bélicos, decididos e implementados por los grupos de poder (ver p. ej. Echeverría 2003). Sin embargo, lo que Nowotny propone parece ser una tomada de conciencia de las nuevas circunstancias de producción del conocimiento científico que permita, no meramente asumirlas como inevitables, sino - considerando que diversos aspectos de la "contextualización" de la ciencia parecen contrarios a su integridad epistémica y a su uso democrático - canalizarlas en la dirección de "repensar" la ciencia, como el título de su libro lo enuncia.

\section{Cambios epistemológicos implicados por el conocimiento robusto}

Cabe señalar inicialmente que, a pesar de la frecuencia con que palabras como "epistemología" y "epistemológico" son empleadas en el libro, sus referentes no son claros. Nowotny parece aludir, de manera asistemática, a asuntos tales como el objeto ( $u$ objetos) del conocimiento científico, la validez del mismo, la finalidad de la ciencia y las metodologías de investigación. Una alegada transformación de la "epistemología" parece tener que ver con los diferentes objetivos a que sirve la ciencia en su "modo 2". Tiene que ver con la organización de la investigación, con la implementación del conocimiento (en la mayoría de las investigaciones hoy no hay distancia entre descubrimiento y aplicación) y con la incertidumbre traída por las innovaciones, así como con nuestra ambivalencia en relación a ellas (abrazarlas y temerlas, pues "todo cuanto es conocido será inevitablemente implementado"; op. cit.: 183). Y la "epistemología" debe ser apreciada sociológicamente, lo que significa tomar en cuenta las imágenes sociales de la ciencia (no sólo por parte de los científicos, sino de todos los que intervienen en la producción del conocimiento, así como los usuarios y los afectados por aplicaciones del mismo). Una epistemología social tiene que ver, 
entre otras cosas, con la relación entre las imágenes (socialmente condicionadas) de la ciencia y el conocimiento producido (id.: 194). Esas visiones pueden moldear el cuerpo del conocimiento y su núcleo (id.: 95). La imagen tradicional (ciencia en busca de la verdad, que acumula conocimientos comprobados, que se articula en disciplinas, etc.) estaría siendo substituida por otra, o mejor, otras imágenes, correspondientes a las muy diversas "culturas epistémicas" (Knorr-Cetina 1999). En todo caso, las imágenes de la ciencia median entre su práctica y la actividad social en general. Y si bien en toda época los legos, posiblemente, opinaron sobre la ciencia, actualmente esa opinión tendría mucho más peso en la confirmación de la práctica científica (Nowotny 2010: 188-89). Lo que se entiende por "buena" ciencia pasa a ser algo diferente.

De acuerdo con Nowotny, el "núcleo epistemológico" de la nueva práctica científica está "vacío", o, desde otro punto de vista, "repleto [crowded] y heterogéneo". En todo caso, está en permanente cambio (Nowotny 2010: 179 y 259). Los autores admiten anticipadamente que éste es "el más radical de sus argumentos" y "el más difícil de aceptar". Su argumentación es la siguiente: los cambios co-evolutivos (cienciasociedad-cultura) y la contextualización de la ciencia (en virtud de las demandas sociales específicas) tienen como consecuencia la necesidad de re-conceptualizar la confiabilidad del conocimiento científico y cuestionar sus fundamentos epistemológicos (id.: 179). Eso porque el "núcleo de valores cognoscitivos y sociales" que definían la "buena ciencia" fue "invadido" por fuerzas extra-científicas y dispersado en "ambientes de conocimiento" (knowledge environments) cada vez más heterogéneos.

El "núcleo" aludido parece consistir en la convicción de que haya verdades básicas, conocimientos que permanecen y permiten la acumulación del saber (como p. ej. leyes fundamentales de la Física). A diferencia del núcleo, las partes soft de la ciencia serían aquello que va cambiando como resultado de las nuevas investigaciones. Las "fuerzas extra-científicas" que habrían "invadido" aquel núcleo serían, a lo que parece, los propósitos, intereses y poderes sociales que reclaman la intervención de la ciencia ante problemas que deben ser resueltos. Y los "ambientes de conocimiento" en juego serían (conjeturo) las ideas y procedimientos cognoscitivos propios de grupos o sectores sociales, profesionales, etc.

La afirmación del carácter "vacío" o "repleto" del "núcleo epistemológico" de la ciencia parece tener que ver con lo siguiente. La ciencia tradicional, para Nowotny, "es primariamente un método" (id.: 246), lo que parece significar que, tradicionalmente, los aspectos metodológicos de la ciencia fueron más importantes que los epistemológicos. Da la impresión de que se admite la existencia, en la ciencia tradicional, de una metodología general de investigación (al menos en las ciencias naturales), pues a seguir se afirma que actualmente (en la transición hacia un conocimiento robusto) el núcleo de la ciencia está "repleto de una variedad de normas y prácticas que no pueden ser fácilmente reducidas a una única metodología gené- 
rica, o más ampliamente, a culturas privilegiadas de investigación científica" (id.: 247). Además, el "núcleo" está, como dije, continuamente cambiando, "siendo vaciado y llenado nuevamente con nuevos valores, normas y prácticas" (id.:259), como resultado de la confrontación de la tradición dominante occidental iluminista en la ciencia (que se pretende universal y aspira a resultados invariables), con tradiciones locales, alternativas e híbridas (ibíd.). ${ }^{4}$

Lamentablemente, no se encuentran fácilmente en el libro ejemplos de normas, prácticas y valores científicos substituidos por otros, más apropiados. ${ }^{5}$ La única referencia que se encuentra es a que no tendrá ya sentido buscar "una verdad única", sino "verdades más refinadas y sutiles" (id.: 259). Eso parece justificar dos afirmaciones que no dejan de ser desconcertantes: la de que la riqueza de las tradiciones de conocimiento que influyen la producción de conocimiento robusto haría que "el riesgo de colapsar en relativismo sea realmente insignificante", y la de que, aunque en el conocimiento robusto todo siempre "dependa" [de las circunstancias, valores, etc., supongo], "no se trata de que [en él] 'todo valga" (id.: ibíd.).

El "núcleo" (eventualmente resistente a la contextualización, como se afirma en la p. 194) inspira a Nowotny la sospecha de ser tan sólo un "escudo" para proteger la ciencia de "potenciales ataques" y "críticas ignorantes" (id.: 196). Por otra parte, "se reduce a un pequeño número de leyes irrefutables e invariables, que resisten la contextualización en un ambiente más amplio" (ibíd.). El núcleo se muestra "vacío" en circunstancias en que un conocimiento científico puede ser usado en otros contextos culturales sin consideración de las normas y valores supuestamente imprescindibles al rigor científico (id.: 187).

De todos modos, las transformaciones epistemológicas alegadas se refieren también a una noción central en la ciencia: la de la objetividad del conocimiento. La ciencia tradicional aspiraba a alcanzar paulatinamente una realidad independiente, inherentemente estructurada, que sería representada fielmente por el conocimiento obtenido. Los objetos de esa ciencia eran definidos por las respectivas disciplinas, y el correspondiente conocimiento se suponía que prescindía de factores "subjetivos" (id.: 64). Para garantizar esa objetividad la ciencia tradicional era "desinteresada", lo que aquí significa separada del contexto. También en este sentido el "modo 2" de investigación se muestra diferente. Los objetos de investigación ya no son definidos tan sólo en términos de una o más especialidades científicas, sino por la acción combinada del equipo de investigadores y otros agentes interesados en su producción. Por eso, en rigor el objeto se produce a lo largo de la investigación (el caso de la investigación genómica sería un ejemplo). Además, los sujetos de la ciencia son incluidos en el resultado, ya sea porque este último implica la visión que los sujetos tienen de la situación-problema, o porque los sujetos forman parte de la investigación, o en fin porque los legos pueden objetar resultados científicos de un modo que estimule una mayor "objetividad" (id.: 208), esto es, confiabilidad y utilidad del co- 
nocimiento. Por lo demás, la confiabilidad reposa antes en la (exitosa) aplicación del conocimiento que en su mera repetibilidad en contextos de laboratorio.

Nowotny advierte que la transformación del conocimiento confiable (en términos tradicionales) en conocimiento robusto no significa abandono de las "condiciones y procesos básicos" por los que el conocimiento científico es evaluado. "El conocimiento confiables permanece como la indispensable 'condición sine qua non' del hecho de que la ciencia 'funciona", afirma (id.: 246). ${ }^{6}$ Sin embargo, el "reduccionismo" de la práctica científica tradicional, que limita la apreciación de la validez del conocimiento al grupo de pares (ni siquiera a los científicos en general), tendría como consecuencia el carácter inherentemente incompleto de ese conocimiento. Esta incompletud no es tan sólo la de un saber que será seguramente superado en el futuro (como es normal que lo sea), sino la de un saber socialmente impugnado y no enteramente controlado por los científicos (ibíd.). Como resultado, la validez del conocimiento no puede más ser definida por normas ligadas a disciplinas, sino "ser sensible a una variedad mucho mayor de implicaciones sociales" (ibíd.).

\section{Verosimilitud de la reivindicación}

El diagnóstico y la correspondiente propuesta de Nowotny han sido criticados, creo que correctamente, sobre todo por el carácter vago y retórico (en todo caso, programático) de sus afirmaciones (Weingart 2008). En efecto: no sólo es dudoso que los ejemplos de prácticas científicas que el libro contiene puedan probar inequívocamente su diagnóstico, sino que también los enunciados teóricos parecen difíciles de compartir (y hasta de entender, como se puede percibir por la exposición precedente), en particular, la tesis central de que el núcleo epistemológico de la ciencia esté quedando vacío o repleto de otras prácticas cognitivas.

Sin embargo, la cuestión o las cuestiones que enfoca son reales. La ciencia viene sufriendo conocidas transformaciones al acentuarse su vinculación a proyectos tecnológicos que responden a intereses industriales, comerciales, políticos, bélicos (la ya mencionada "tecnociencia"). ${ }^{7}$ En ese proceso, consideraciones sobre la utilidad del saber pasan a ser más importantes que las relativas a su justificación teórica. Aunque se suponga que un conocimiento eficaz es señal de una buena comprensión de la realidad a la que se aplica, no parece haber, por parte de los científicos y técnicos comprometidos en proyectos tecnológicos, mucha preocupación acerca de los criterios por los que se identificaría la verdad del conocimiento que manejan. ${ }^{8} \mathrm{Y}$ los nuevos conocimientos teóricos a menudo aparecen como subproductos, intencionales o no, de proyectos tecnológicos.

Es también un hecho que los equipos que encaran la solución de determinado problema práctico no están constituidos tan sólo por científicos (menos aún, de una

Principia 16(2): 319-340 (2012). 
única especialidad), sino por diferentes profesionales (junto a los científicos participan técnicos, ingenieros, administradores, abogados y otros agentes, según el caso). La opinión de los legos es, de acuerdo con la índole dos proyectos, investigada, consultada o ignorada, pero los legos, a su vez, participan de proyectos o los objetan, así como objetan resultados científicos).

Tampoco cabe dudar de que el conocimiento científico es incompleto, frecuentemente incierto en su aplicación y consecuencias, y que su validez está amenazada por la distancia entre las idealizaciones y comprobaciones experimentales, por un lado, y los sistemas reales y las situaciones complejas a que el conocimiento debe ser aplicado (Strand 2008). Además, no es posible desconocer que el universalismo, el realismo y la aspiración a una visión integrada de la realidad, propios de la ciencia básica tradicional, son objeto de una constante desconfianza filosófica. Las leyes de la física "mienten" (N. Cartwright, 1983), postular la existencia de las entidades teóricas parece superfluo (B. V. Fraassen, 1980), la aparente unidad del mundo se revela como un "desorden de las cosas" (J. Dupré, 1993). Como si fuera poco, esa ciencia aparentemente desinteresada, movida sólo por una sana curiosidad humana, es sospechosa de mantener un inconfesado vínculo con la voluntad de controlar la Naturaleza (H. Lacey, 1999).

Last but not least, hay una reclamación creciente por parte de grupos sociales, cuando no de culturas enteras (me refiero a las culturas dominadas por las potencias occidentales), relativa a la justificación de las investigaciones científicas y los productos tecnológicos. Los ciudadanos, los consumidores, las víctimas de la civilización tecnológica exigen, cada vez más, ser informados y poder participar de las decisiones relativas al fomento de la ciencia y la tecnología. "Democratizar la ciencia" es la expresión que sintetiza esa reclamación, que implica una conciencia de la necesidad de saber para poder, al mismo tiempo que una sospecha de que la imagen (oficial) de la ciencia sea engañosa, que sus verdades no sirvan ipso facto para mejorar la vida humana, que no sean tan sólidas y distantes del conocimiento vulgar que este último no pueda contribuir a perfeccionarlas, que sea posible conjugar rigor científico y propósitos y valores extra científicos (Radder 2010).

Por lo tanto, a pesar de las limitaciones de su formulación la tesis de Nowotny se refiere a una situación real y a una reivindicación justificada. Resumiendo (un tanto arriesgadamente) esa reivindicación, la tesis aquí examinada equivale a la propuesta de transformar una ciencia teóricamente ociosa y prácticamente cooptada por los sectores de poder (la ciencia a que se oponen, sin mucho éxito a no ser el crítico, las ideologías políticas - marxismo, feminismo - y culturales, como el post-modernismo), en una ciencia democráticamente decidida e implementada, que responda al interés público. ${ }^{9}$

Principia 16(2): 319-340 (2012). 


\section{Analizando los alegados cambios epistemológicos ${ }^{10}$}

\subsection{Lo que se entiende por ciencia, por "buena ciencia", y por Epistemología debe mudar}

Ese cambio sería necesario, según Nowotny, no sólo porque la práctica de investigación está cambiando (de ser una actividad ejercida por profesionales de una misma disciplina a consistir en trabajos de equipos multi-profesionales), sino también porque la imagen popular de la ciencia la influye, y porque la actividad científica es objetada por la sociedad.

La noción tradicional de la ciencia (común a científicos y a numerosos filósofos) es epistemológicamente realista (la ciencia alcanza un conocimiento verdadero - $\mathrm{o}$ al menos confiable - de una realidad independiente, inherentemente estructurada). Ese conocimiento es una representación del correspondiente objeto, paulatinamente mejorada. Como es sabido, las dificultades teóricas del realismo suscitaron doctrinas epistemológicas alternativas, sobre todo el coherentismo (verdad o confiabilidad tiene que ver con la inter-vinculación de nuestras creencias, y no con una supuesta realidad transcendente) y el pragmatismo (denominamos verdaderas las creencias eficaces para producir los cambios que deseamos). ${ }^{11}$ Es también notorio que la Epistemología (especulativa) tradicional tiende a ser substituida por la Epistemología Naturalizada, que aspira a fundamentarse en el proceso efectivo de adquisición del conocimiento, científicamente esclarecido. Además, la denominada Epistemología Social cuestiona la concepción tradicional de la Epistemología que toma como objeto de reflexión el sujeto cognoscente individual, viendo en la cognición un proceso que involucra siempre la dimensión de lo colectivo. Evidentemente, la posición de Nowotny apela al coherentismo (su base parece ser Rorty 1991), vinculado por motivos obvios - el conocimiento robusto obedece a problemas prácticos - al pragmatismo. La tesis del conocimiento robusto se afilia a la Epistemología Social de S. Fuller (1997), y busca también subsidios en la Sociología de la Ciencia de K. KnorrCetina (1999). Y al pretender describir el modo como la ciencia, de facto, existe en la actualidad, colocase del lado de la Epistemología Naturalizada.

Creo que la Epistemología Naturalizada es una saludable reacción (semejante a la ocurrida en otras áreas filosóficas, como la Ontología) contra reflexiones apriorísticas que tal vez hayan fomentado problemas insolubles (como el de superar el escepticismo). Además, considero que la Epistemología Social, al menos en cuanto a su inspiración, es necesaria para trabajar sobre una imagen tan realista (en sentido vulgar) del conocimiento como sea posible. Sin embargo, el riesgo de la Epistemología Naturalizada es minimizar, o hasta suprimir, la dimensión normativa de la Epistemología (como alerta, entre otros, H. Longino, en Longino 2002:10). Lo mismo reza para la Epistemología Social. En otras palabras: no basta lo que de

Principia 16(2): 319-340 (2012). 
facto es considerado como conocimiento en determinadas circunstancias. Es menester saber lo que de iure merece ser considerado como tal. Rorty (1991), al defender la "solidaridad" contra la pretensión de "objetividad", ${ }^{12}$ hace del consenso, paulatinamente ampliado, la única base del conocimiento. Para Nowotny, el conocimiento robusto supone y exige un consenso entre los diversos agentes (científicos, técnicos, administradores, legos, etc.) que lo legitima. La eficacia del saber robusto está de algún modo subordinada a ese consenso (ella sería, digamos, la eficacia legítima o legitimada). Si juntamos a eso el proclamado cambio en la noción de objetividad científica (a la que me referiré más adelante), poca duda queda de que las diversas prácticas de conocimiento robusto serían auto-legitimadoras.

La auto-legitimación puede ser vista de dos maneras. Si la juzgamos desde la perspectiva de la ciencia académica, entendida de acuerdo con el realismo, la autolegitimación es inaceptable (el éxito práctico, aunque sancionado por la satisfacción social, no equivale a la verdad). Si la juzgamos desde la perspectiva del conocimiento robusto, significa que la ciencia abandonó - saludablemente - la pretensión de ser la voz de la verdad que debe ser necesariamente obedecida, para transformarse en una colaboradora, aunque muy importante, en un determinado proyecto humano deseable. ${ }^{13}$ Si el conocimiento científico "funciona" de manera que satisfaga a los diversos participantes (y los involucrados) en un proyecto social, eso configuraría un caso de "buena ciencia", supongo. En cuanto a la realidad implicada en ese proceso de conocimiento/transformación/invención, una de dos: o su correcta identificación no estaría en cuestión, o esa identificación estaría garantizada por la colaboración de los diversos agentes (en vez de ser proporcionada por una disciplina académica, v.g. la Física o la Sociología).

En otras palabras: lo que la tesis del conocimiento socialmente robusto parece postular, en este particular, es que lo que se deba entender por una adecuada comprensión del mundo no proviene (o no proviene necesariamente) de la investigación especializada, sino de la alianza de ella con otras formas de conocimiento, manipulación y apreciación de la realidad. ${ }^{14}$ Ese parece ser el sentido de la afirmación de Nowotny de que el conocimiento "confiable" (= el certificado por los pares, dentro de una disciplina) continúa siendo el presupuesto del conocimiento "robusto".

La propuesta de Nowotny es, por lo menos, verosímil. Desde la perspectiva tradicional, si un conocimiento tenido por válido no funciona en una situación concreta, se supone que se debe a dos razones, principalmente: el conocimiento científico es general y "abstracto", en oposición a las situaciones por definición particulares, y estas últimas pueden tener características que operan como obstáculos para la aplicación de aquel conocimiento general. No pudiendo dudar de ese conocimiento (si fue confirmado por los científicos reiteradamente), no hay otra salida sino la de modificar la situación para que el conocimiento funcione (suponiéndose que el mismo sea imprescindible). La "lectura" tradicional de ese proceso consiste en ver allí una 
operación en que el mejor conocimiento disponible se impone (teórica y prácticamente), siendo por eso la solución alcanzada la mejor posible, a pesar de eventuales limitaciones de ella o de efectos negativos no intencionales. ${ }^{15}$

El pluralismo de opiniones sobre la "realidad" es considerado saludable en Nowotny como protección contra el "reduccionismo" de la ciencia tradicional. No cuesta concordar, en principio, con esa protección. Es de veras preocupante que se diagnostique que tal o cual situación ambiental, humana o de ambos tipos, como "no siendo más que", en última instancia, algo que responde a las leyes de la física, a la estructura química, a los genes, a la clase social, etc. La estrategia tecnológica correspondiente a esa mirada simplificadora es siempre la adopción de medidas que en alguna medida fuerzan la "realidad" a adecuarse a conocimientos abstractos o genéricos, sin contar con que los mismos pueden responder a determinados intereses sociales. ${ }^{16} \mathrm{Y}$ de manera alguna puede darse por obvio que, en toda situación, el conocimiento del físico, el biólogo, el psicólogo, sea necesariamente mejor (?) que el saber de un constructor, la experiencia de un paciente o de un enfermero, la observación de un padre o de un profesor. Desde la perspectiva del conocimiento robusto, "la mejor solución posible" de un problema práctico no sería decidida por un agente privilegiado, sino por un consenso de diversas apreciaciones del problema y de la solución.

Nowotny y sus colegas no son los únicos que proponen un cambio de concepción de lo que sea un conocimiento apropiado a proyectos sociales. Lacey (Lacey 1999 y 2008, 2010), denunciado lo que entiende por velado compromiso de la ciencia moderna con el control de la Naturaleza y la correspondiente no neutralidad de las investigaciones, sugiere que el conocimiento científico (natural) sea conjugado con otros saberes (ciencia social, saberes tradicionales de la comunidad) al buscarse una solución satisfactoria de problema sociales ("conocimiento abarcador" vs. "conocimiento extensivo"). La diferencia (no pequeña) entre Nowotny y Lacey consiste en que este último preserva explícitamente la importancia de la apreciación de las ideas científicas por criterios epistémicos tradicionales ("imparcialidad" de la ciencia), mientras que Nowotny es vago y retórico a propósito de este asunto.

\subsection{La validez del conocimiento científico debe ser concebida de modo diferente}

En la ciencia académica un conocimiento es aceptado como válido por el juicio de los pares (de una misma disciplina o sub-área). La opinión de otros científicos es secundaria, y relevante únicamente hasta el punto en que haya afinidades entre las disciplinas y suficiente información del científico en particular sobre el asunto en cuestión. La opinión de los legos, por incompetente, es irrelevante. Se supone que el saber científico, o bien desautoriza el saber del lego, o constituye la verdadera razón de su eventual validez. Y aunque diversos criterios entren en la apreciación de la

Principia 16(2): 319-340 (2012). 
validez teórica (consistencia, coherencia, pertinencia de la metodología, justificación de las evidencias, etc.), la repetibilidad de las observaciones, de los experimentos, los cálculos y las demostraciones es la piedra angular de la confiabilidad del saber científico.

Nowotny argumenta que, en el conocimiento robusto, más importante que la posibilidad de repetición será la contextualización. ${ }^{17} \mathrm{El}$ conocimiento será tanto más confiable cuanto más se muestre válido más allá de los "espacios estériles creados por la ciencia experimental y teórica” (op. cit.: 168). La contextualización reivindicada implica que la relación entre conocimiento científico y saber vulgar debe ser repensada, así como la colaboración entre disciplinas científicas (interdisciplinaridad), y hasta la vinculación entre las prácticas cognoscitivas y otro tipo de intereses (económicos, sociales, políticos, religiosos ...).

Creo que el problema epistemológico que se suscita aquí es el de cómo conciliar los criterios usados por las diversas partes. Cómo hacer, por ejemplo, que afirmaciones discrepantes, presumiblemente fundamentadas en "hechos" o en la "experiencia" (supongamos, de un químico y un cocinero, o de un biólogo y un criador de animales, pero también de un físico y un geólogo, y de un sociólogo y un abogado), dialoguen y resulten en consensos. Nowotny, recordemos, no niega que las cualidades de consensibilidad y consensualidad del conocimiento deban ser preservadas en su modalidad "robusta". Por otra parte, afirma que el núcleo epistemológico del conocimiento robusto está "vacío" o "repleto" de prácticas diversas. Que está (o estaría) repleto, no hay duda. Que esté vacío significa, como vimos, que la aplicación de las partes hard de la ciencia a diferentes contextos no requiere justificación epistemológica. Pero, ¿cómo conseguir que, al trabajar en equipo, la opinión del científico se combine con la de los no científicos de modo que todas las partes acepten el resultado como satisfactorio sin imponer el conocimiento científico como privilegiado cuando entra en conflicto con otros saberes o prácticas? ¿Cómo diferenciar creencias y procedimientos (consensualmente) entendidos como correctos, exitosos y (no por último) honestos, de creencias y procedimientos incorrectos, fallados y fraudulentos? ¿Cuáles serían los criterios de un saber robusto (que sería tato un "saber-que" cuanto un "saber-como")? Imagino que deba haber algo así como meta-criterios (con relación a los criterios científicos tradicionales, y a criterios de otras áreas) para resolver situaciones de conflicto, como discrepancias entre datos científicos diversos, entre datos científicos y no científicos, entre exigencias lógicas o cálculos matemáticos y situaciones vividas, entre previsiones científicas y vulgares, etc. No parece fácil dispensar todo criterio y "dejar el núcleo permanente vacío", como ya vimos recomendar. Tampoco resuelve la cuestión declarar que los criterios epistemológicos serían "circunstanciales". 


\subsection{La declinación de la autoridad epistémica de la ciencia ${ }^{18}$}

El punto anterior nos lleva al presente. Como vimos, para Nowotny la ciencia parece perder (o ver disminuida) su autoridad para definir la realidad o la Naturaleza. ${ }^{19}$ Además de vincular esa declinación al aumento de la utilidad de la ciencia, Nowotny ofrece otros argumentos: las prácticas científicas (y sus resultados) son muy diversificadas; la ciencia de punta no sabe cómo entender las partículas subatómicas; los objetos de investigación son inseparables de la propia investigación; el descubrimiento fue substituido por la innovación; las imágenes populares de la ciencia y las imágenes autorizadas por la comunidad científica son difíciles de distinguir... En adelante, la ciencia entra tan sólo como un colaborador más en los equipos que buscan resolver un determinado problema, ya se trate de proteger un ambiente natural o cultural, prever catástrofes y adoptar medidas defensivas, producir nuevas armas, otros medios de comunicación, mejores alimentos o mayor cantidad de los mismos. La "realidad" que se desea proteger, monitorar, transformar no puede ser identificada solamente por la opinión (que a eso se reduce) de los científicos, sino por el trueque de opiniones entre ellos y - supongamos - los ingenieros, los técnicos, los usuarios, y los favorecidos o perjudicados por el resultado a ser alcanzado. También influiría, aunque tal vez en menor medida, esa definición de la "realidad" la opinión de otros participantes de un proyecto, tales como los que proporcionan el capital necesario, los abogados, los administradores, los designers, los consultores de la opinión pública, etc. Y, siempre de acuerdo con las situaciones, podría intervenir también la opinión de otros agentes tales como fieles de una determinada religión, ${ }^{20}$ representantes de culturas y sub-culturas específicas, artistas y (no cuesta imaginar) hasta filósofos.

Nowotny parece no lamentar esa declinación (y hasta parece entenderla como verdadera realización del ideal iluminista de ciencia socialmente útil) (op. cit.: 259). Sin embargo, la autoridad de una actividad orientada a la obtención de un conocimiento confiable acerca del mundo, independiente de intereses no cognoscitivos, está lejos de ser irrelevante o fácil de substituir. A pesar del peligro de reduccionismo latente en toda confianza excesiva en la ciencia esto es, en la visión de una dada disciplina o sub-disciplina sobre un sector de la realidad), se espera de la ciencia un conocimiento confiable, como reconoce Nowotny. ¿Qué significa eso? No sólo un saber que permita fundamentar, convenientemente, proyectos prácticos, sino también que permita entender el mundo, natural y social, de manera satisfactoria. Y esa satisfactoriedad, a su vez, implica no considerar convincentes las explicaciones vulgares (tradicionales, etc.) para nuestros interrogantes. ${ }^{21}$ Además, la confiabilidad del conocimiento debe servir de fundamento a la crítica de pretendidos saberes y prácticas. Por eso John Ziman (Ziman 2002 y 2007) defendía la necesidad de la ciencia académica (o "modo no instrumental" de la ciencia) en razón de que precisamos de

Principia 16(2): 319-340 (2012). 
un árbitro competente y relativamente imparcial para decidir las cuestiones sociales generadas por la innovación tecnológica. ${ }^{22}$

Es por esa razón que la autonomía cognoscitiva de la ciencia es tan importante, o sea, la necesidad de que tan sólo criterios epistémicos sean relevantes al juzgar la validez teórica del conocimiento producido. Generalmente - y Nowotny no es una excepción - la autonomía de la ciencia es pensada solamente en su aspecto institucional, vale decir, en la exigencia de que únicamente los científicos puedan decidir qué problemas deben ser investigados, cuáles metodologías son convenientes y cuáles soluciones pueden ser aceptadas, sin intervención externa (influencia política, económica, religiosa ... ). Con respecto a esa noción de autonomía Nowotny y sus colegas afirman que "debe ser preservada", por ser "precondición de la formación y perseverancia de las identidades científicas [de las disciplinas, presumiblemente]" y "precondición esencial de la creatividad científica" (op.cit.: 232), pero afirma también que en el Modo 2 de investigación, la autonomía adoptará "formas altamente localizadas", debiendo ser "justificada en cada caso y para cada proyecto individual de investigación" (ibíd.). Parece que se trata de impugnar la autonomía científica entendida como rechazo a priori y genérico de toda influencia "externa", substituyéndola por una concepción de la ciencia en que se decidirá, caso a caso, lo que sea una influencia justificada en la agenda de la investigación. Ocurre que, en la autonomía entendida cognoscitivamente, la influencia externa no es sólo potencialmente perjudicial, sino impertinente. Si una teoría es verdadera (o razonablemente comprobada), si un hecho está constatado, si una explicación es satisfactoria, si un experimento fue exitoso, etc., que ellos sean o no políticamente convenientes, moralmente aceptables, tecnológicamente fáciles de implementar, económicamente rentables, piadosos a los ojos de determinado credo, etc., simplemente no viene al caso.

La (velada) pérdida de autonomía cognoscitiva de la ciencia que interviene en proyectos prácticos puede no ser tan importante (al fin de cuentas, realizaciones tecnológicas tradicionales se sirven de teorías superadas, en caso de que sean útiles y menos onerosas), pero nada indica que el Modo 2 de ciencia excluya la búsqueda de conocimiento como finalidad (al menos temporariamente) primordial. La investigación genética, o la búsqueda del boson de Higgs ilustran este punto. En esos casos, que criterios cognoscitivos (y no tecnológicos, económicos, etc.) sean los decisivos es algo imprescindible. Pero Nowotny nada dice a ese respecto.

\subsection{La nueva noción de objetividad}

Vimos que, según Nowotny, la concepción tradicional de la objetividad científica (como actitud que permite entender el mundo de manera libre de perturbaciones subjetivas, formulando ese entendimiento de tal forma que sea universalmente admitido)

Principia 16(2): 319-340 (2012). 
es también cuestionada en el paso del Modo1 al Modo2 de conocimiento.

Nowotny hace notar (siguiendo a Daston y Galison 1992) que, aunque la noción tradicional de objetividad sugiera que la ciencia alcanza una realidad independiente, la práctica efectiva de la ciencia a lo largo de la historia consistió "en un gradual proceso de compleja objetificación" (Nowotny 2010: 169), cuyo producto es el "conocimiento confiable". Nuestros autores admiten que la actitud objetiva es todavía el mejor modo de obtener conocimiento confiable, pero creen que, al pasar del Modo 1 al Modo 2 de ciencia, la noción de objetividad debe ser modificada. En vez de aspirar a conocimientos que sean "objetivos" porque sean transcendentes a todo contexto, la ciencia socialmente robusta ha de procurar una objetividad local. Esa definición parece implicar - como ya fue mencionado - que lo que se deba considerar como elementos perjudiciales o benéficos a un conocimiento confiable (a propósito de intereses que influyen la investigación) no podrá ser determinado $a$ priori, sino en función del propósito de la investigación particular. Y la repetibilidad del conocimiento deberá extrapolar los procedimientos válidos en una determinada especialidad científica para conjugarlos con prácticas extra-científicas. Nowotny cita como ejemplos la necesidad que tuvieron los científicos y tecnólogos de aceptar las observaciones de los criadores de ganado al enfrentar las consecuencias de la lluvia radioactiva producida por el accidente de Chernobyl, y la interacción de médicos y pacientes de SIDA en la búsqueda de cura para la enfermedad (Nowotny 2010: 208 a 211). Por otra parte, y como ya mencioné, el objeto de la investigación no estará definido desde el comienzo, como en una investigación académica convencional, sino que irá siendo reformulado a lo largo de la investigación, como consecuencia de las "negociaciones" entre los agentes que participan del equipo. ${ }^{23}$ Lo que no impide que subsista en el conocimiento "robusto" una tensión entre la objetividad y la "solidaridad", representando esta última las "presiones de la "contextualización" y la primera, la fuerza del conocimiento especializado. Tal vez por eso Nowotny afirma que, aunque la objetividad de la ciencia debe ser preservada, ella "irá a ser transformada más allá de su reconocimiento" (id.: 232).

Se sabe que la noción de objetividad científica es blanco de constantes y variadas críticas. Diversos estudios indican que no siempre esa noción estuvo vinculada a la práctica científica, y que no siempre fue entendida de la misma manera (Cupani 2011). Por otra parte, aunque es intuitivamente asociada con la ciencia "pura" y el realismo epistemológico, la objetividad no está necesariamente ligada a ellos. Cabe aspirar a conocimientos objetivos (válidos intersubjetivamente) que no pretenden ser "copia fiel" de la realidad a que se refieren. Vale decir: es posible reconocer cierta dosis de verdad al constructivismo epistemológico. Este último admite al menos dos variantes: el constructivismo externo (social) y el constructivismo que podríamos denominar interno, porque tiene que ver con las prácticas específicas de la ciencia. El constructivismo social, cuando no es radical, ${ }^{24}$ constituye a mi ver un saludable 
correctivo de un realismo (aún en cierta medida) ingenuo. No es ya posible entender la ciencia sin admitir su carácter de tarea social, que se refleja de alguna manera tanto en los asuntos investigados como en los resultados obtenidos. En cambio, el constructivismo interno se expresa, por ejemplo, en la observación formulada hace ya casi un siglo por G. Bachelard, de que las substancias químicamente puras son una producción teórico-técnica (Bachelard 1972). Y cabe mencionar también que la transformación del objeto de conocimiento a lo largo de la investigación (como Nowotny afirma que sucede en el conocimiento robusto) tiene su paralelo en la ciencia tradicional. La evolución de la investigación de la naturaleza de los átomos (desde su postulación metafísica en la Antigüedad hasta los sucesivos modelos teóricos con sus correspondientes testeos experimentales) es un ejemplo que viene fácilmente a la memoria. ${ }^{25}$

Por consiguiente, una noción actualizada de la objetividad científica debe incluir, me parece, un reconocimiento de la manera (metodología, etc.) en que se llega a resultados "objetivos", de las idealizaciones o aproximaciones que esos resultados contienen y de los condicionamientos sociales inevitables de la actividad científica. Sin embargo, la principal diferencia entre la investigación tradicional, académica, y la investigación en el Modo 2 estaría en el carácter no disciplinario de esta última, con las consecuencias correspondientes. En una ciencia disciplinaria, resultados objetivos son así definidos por los pares, y se supone que, porque reflejan aspectos constantes de la realidad (leyes, estructuras, clases), esos resultados valen para cualquier situación que involucre el mismo tipo de acontecimientos (físicos, químicos, biológicos, etc.). En una investigación "robusta", el conocimiento objetivo sería aquel que mejor se adecuara a la situación-problema, de acuerdo con el juicio (compatibilizado) de los diversos agentes que intervienen, sin excluir la posibilidad de transferir ese know how para situaciones análogas.

En rigor, más que definir un nuevo tipo de objetividad, los defensores de un conocimiento robusto están cuestionando, de otro ángulo, el papel y la autoridad del conocimiento objetivo (en sentido tradicional) en proyectos sociales. Ellos no son, ciertamente, los únicos que lo hacen: filósofos hermenéuticos, científicos sociales críticos y epistemólogas feministas cuestionan la ciencia objetiva con otros y diversos argumentos. ${ }^{26}$ La crítica de Nowotny se aproxima, me parece, a la de Lacey, antes citada, del "conocimiento extensivo", o sea, aquel que entiende los fenómenos naturales como resultantes de estructuras y procesos subyacentes, de carácter general, formulables matemáticamente y detectables en operaciones de laboratorio. Ese tipo de conocimiento sería insuficiente (y hasta inapropiado) para resolver cuestiones prácticas complejas, que involucran diferentes aspectos de la realidad (físicos, biológicos, sociales) y comprometen el bienestar humano. La insuficiencia del "saber extensivo" estaría vinculada a que la ciencia así concebida busca siempre, aunque sea inconfesadamente, el control de la realidad a que se refiere. Cabe, sin embargo, 
reiterar que Lacey no niega el valor epistémico de ese tipo de investigación: lo que hace es cuestionar su aplicación indiscriminada, como panacea, en proyectos tecnocráticos. Por otra parte, las corrientes teóricas que cuestionan la objetividad, antes mencionadas, lo hacen en nombre de un saber que no podría ser alcanzado por la actitud objetivadora (la comprensión del significado de los fenómenos humanos, o la superación de una percepción alienada o prejuiciosa de la vida social). Es decir que, a diferencia de Nowotny, otros críticos de la objetividad como característica de la ciencia la discuten en nivel epistemológico. En contraste, y a pesar del constante uso de las expresiones "epistemología” y "epistemológico", Nowotny parece referirse siempre a proyectos en que predomina el interés práctico. Nowotny admite (op.cit.: 169) que la noción de objetividad tiene varias dimensiones: metodológica, epistemológica, moral. El conocimiento objetivo es el obtenido mediante procedimientos definidos que alcanza correctamente su objeto, que está relativamente libre de elementos subjetivos. O sea, que es imparcial o exento. De esas dimensiones, la metodológica se transformaría, pues como vimos, la repetibilidad en términos de la metodología aceptada en una disciplina sería substituida por múltiplos testeos. La dimensión epistemológica cambiaría también, pues no es la finalidad propia de un conocimiento práctico o aplicado caracterizar la realidad, sino transformarla. Y en lo que respecta a la dimensión moral, en vez de aspirarse a la imparcialidad, se buscaría el compromiso entre los diversos intereses. Francamente, Nowotny tiene razón al afirmar, como ya fue mencionado, que el concepto de objetividad cambiaría "más allá de todo reconocimiento".

\section{5. ¿Un nuevo tipo de ciencia?}

Dentro del más amplio ambiente en que la ciencia tendrá que funcionar futuramente... una ciencia desencarnada y auto-organizadora que aspira a descubrir reglas invariables y acumular conocimiento precisará ser complementada, si no substituida, por una nueva visión de la ciencia, ricamente contextualizada, socialmente robusta y epistemológicamente ecléctica (Nowotny 2010: 198, énfasis mío).

A primera vista, la propuesta de un conocimiento robusto parece significar el fin de la ciencia académica, como investigación desinteresada de la realidad, y su substitución por objetivos prácticos, democráticamente decididos. Como ya dije, Nowotny da a entender que, así vista, la ciencia robusta sería la verdadera realización de los ideales iluministas (al contrario de lo que piensan los defensores de la ciencia académica (id.: 204)).

Es difícil concordar con esa convicción sin abandonar los criterios epistemológicos tradicionales, así como las normas mertonianas, tal como ya fue mencionado. 
Nowotny insinúa constantemente que algunos de esos criterios subsisten en otra forma. Por ejemplo (ya lo vimos), la repetibilidad del conocimiento objetivo sería entendida, no más en función de los métodos de una única disciplina, sino de múltiples testeos del conocimiento supuestamente alcanzado. Pueden imaginarse transposiciones análogas para criterios como el de fecundidad, el de simplicidad, el de precisión, etc. La norma de desinterés, en cambio, es obviamente descartada, y las normas de universalismo, comunalismo y escepticismo serían (imagino) respetadas o no según fuera conveniente. ${ }^{27}$ Lo que resulta de esa adaptación es difícilmente reconocible como ciencia (básica), en sentido tradicional. Es cuando más ciencia aplicada, si no mera justificación teórica de intereses prácticos.

Es verdad que la ciencia moderna, y su exaltación iluminista, contenían una ambigüedad: por un lado la promesa de un saber verdadero (más allá de las especulaciones y las supersticiones); por otro, un saber útil. Pero la esperanza de un saber verdadero encerraba la convicción de que el mismo incluiría, o traería como consecuencia, un saber actuar, o sea, directrices morales y políticas. Es notoria la crisis de esa expectativa, especialmente después de la euforia positivista: la ciencia objetiva no tiene cómo ofrecernos criterios morales o políticos, ni siquiera razones para cultivar la propia ciencia. Precisamos de reflexión (filosófica, diremos los que nos dedicamos a la Filosofía) acerca de fines y valores, precisamos de crítica (inclusive, de la propia ciencia), y precisamos de acción, para dar sentido a la ciencia. En esa reflexión, sin embargo, la contribución de una ciencia que nos informe, de manera razonablemente confiable, cómo es el mundo, es tan necesaria como la claridad sobre valores y fines, y la disposición a actuar. Una ciencia que no esté amarrada, por lo menos expresamente, a intereses no cognoscitivos.

Estoy consciente de que muchos piensan hoy en día que la ciencia académica no tiene cómo ofrecer esa contribución. Si ése fuera el caso, ¿puede la ciencia "robusta" ocupar su lugar? Ciertamente que no. Puede a lo máximo funcionar como recurso correctivo de la tecnociencia (y será muy valiosa en esa posición), pero a condición de no pretender eliminar la ciencia en el Modo 1, entendida esta última, no según los moldes de tal o cual disciplina, sino como investigación sistemática, empírica y crítica de la realidad. ${ }^{28}$ De otro modo, la ciencia "robusta" significaría, a mi ver, el predominio de un entendimiento reducido (e ideológico) de la utilidad de la ciencia, que simultáneamente estaría abdicando, en forma velada, de sus aspiraciones epistémicas y convirtiéndose en apéndice del poder social, o de los que aspiran al mismo (empoderamiento, empowerment). En el límite significaría que los criterios teóricos de validez del conocimiento perderían su relevancia, substituidos por cualquier versión de la eficacia de ideas y procedimientos, borrándose la distinción, no sólo entre ciencia pura y aplicada, sino también entre ciencia correcta y fraudulenta. ${ }^{29}$ Así considerada, la única diferencia que se percibe entre la ciencia "robusta" y la tecnociencia consiste en que la primera aspira a ser democrática, ade- 
más de eficaz, mientras que la segunda es mero brazo del poder. No se trata de una diferencia pequeña, ciertamente, en términos políticos, pero esa diferencia no llega, de por sí, a la dimensión epistemológica. No constituye un nuevo tipo de ciencia.

\section{Referencias}

Bachelard, G. 1972 [1953]. Le matérialisme rationnel. Paris: P. U. F.

Balmer, B. 1996. Managing mapping in the Human Genome Project. Social Studies of Science 26: 531-73.

Beck, U. 2010. Sociedade de risco. Rumo a uma outra modernidade (trad. de Risikogesellschaft, 1986). São Paulo: Ed. 34.

Brown, J. R. 2001. Who Rules in Science? An Opinionated Guide to the Wars. Cambridge, MA: Harvard U. P.

Cartwright, N. 1983. How the laws of physics lie. Oxford: Clarendom Press.

Cupani, A. 2011. Acerca de la vigencia del ideal de objetividad científica. Scientiae Studia 9(3): 501-26.

Daston, L. \& Galison, P. 1992. The Image of Objectivity. Representations 40: 81-128.

Dupré, J. 1993. The Disorder of Things. Metaphysical Foundations of the Disunity of Science. Cambridge, MA: Harvard U. P.

Echeverria, J. 2003. La revolución tecnocientífica. Madrid: Fondo de Cultura Económica de España.

Fuller, S. 1997. Science. Buckingham: Open U. P.

Gibbons, M. et al. 2010 [1994]. The New Production of Knowledge. Los Angeles: Sage.

Knorr-Cetina, K. 1999. Epistemic Cultures: How the Sciences Make Knowledge. Cambridge, MA: Harvard U. P.

Lacey, H. 1999. Is Science Value-free? London \& New York: Routledge.

— 2008 e 2010. Valores e Atividade Científica. São Paulo, Ed. 34, volumes I e II.

Latour, B. 1986. Science in Action. How to follow scientists and engineers through society. Milton Keynes: Open University Press.

Longino, H. 2002. The Fate of Knowledge. Princeton: Princeton Univ. Press.

Nordmann, A.; Radder, H.; Schiermann, G. (eds.) 2011. Science Transformed? Debating Claims of an Epochal Break. Pittsburgh: University of Pittsburgh Press.

Nowotny, H.; Scott, P.; Gibbons, M. 2010 [2001]. Re-Thinking Science. Knowledge and the Public in an Age of Uncertainty. Cambridge, UK: Polity Press.

Pielke, R. A. 2010 [2007]. The Honest Broker. Making Sense of Science in Policy and Politics. Cambridge, UK: Cambridge U. P.

Radder, H. (ed.) 2010. The Commodification of Academic Research. Science and The Modern University. Pittsburgh: University of Pittsburgh Press.

Rorty, R. 1991. Solidarity or Objectivity? In: Objectivity, Relativism, and Truth. Cambridge: Cambridge U. P.: 21-34.

Shapin, S. \& Shaffer, S. 1985 Leviathan and the Air-Pump: Hobbes, Boyle and the Experimental Life. Princeton: Princeton U.P.

Principia 16(2): 319-340 (2012). 
Strand, R. 2008. In Defense of Some Sweeping Claims about Socially Robust Knowledge. In: Carrier, M., Howard, D. e Kourany, J. (eds.) The Challenge of the Social and the Pressure of Practice. Pittsburgh: University of Pittsburgh Press, pp. 146-59.

Van Fraassen, B. 1980. The Scientific Image. Oxford: Clarendon Press.

Weingart, P. 2008. How Robust is 'Socially Robust Knowledge'? In: Carrier, M.; Howard, D.; Kourany, J. (eds.) The Challenge of the Social and the Pressure of Practice. Pittsburgh: University of Pittsburgh Press, pp. 131-45

Ziman, J. 1995. La credibilidad de la ciencia (trad. de Reliable Knowledge, 1978). Madrid: Ed. del Prado/Alianza.

- 2002 [2000]. Real Science. What it is, and what it means. Cambridge: Cambridge University Press.

2007. Science in Civil Society. Charlottesville: Imprint Academic.

\author{
Alberto Cupani \\ Departamento de Filosofia \\ Universidade Federal de Santa Catarina \\ Florianópolis, SC \\ BRASIL \\ cupani@cfh.ufsc.br
}

Resumo. Em Re-Thinking Science. Knowledge and The Public an Age of Uncertainty (2001) H. Nowotny, P. Scott e M. Gibbons reivindicam um conhecimento científico "socialmente robusto" que corresponda às diversas demandas sociais de nossa época. Tratar-se-ia de um conhecimento que não se limitara a ser epistemicamente confiável, mas que se adaptara às situações a que deverá ser aplicado, tomando além do mais em consideração as conseqiências dessa aplicação. Segundo os autores, essa nova modalidade de ciência, que corresponde ao que em outra obra denominam "Modo 2" de conhecimento, estaria à altura de uma sociedade que não se limita a receber a informação científica ou a requerê-la, senão que também exige participar de sua produção. Nowotny e sus colegas se referem a diversas mudanças epistemológicaos que o conhecimento "robusto" implicaria. Neste trabalho analiso algumas dessas alegadas mudanças.

Palavras-chave: Ciência socialmente robusta; Modo 2 de conhecimento; Helga Nowotny; Peter Scott; Michael Gibbons.

\title{
Notas
}

${ }^{1}$ Se vuelve cada vez más difícil distinguir Estado de mercado, cultura de mass media; imágenes culturales operan como medios de acción política o mercadológica; la ciencia - como agente de innovación - revoluciona la economía y la política; etc. De acuerdo con Nowotny, la ciencia es hoy practicada y debatida en un ámbito que ya no es ni puramente político, ni puramente mercadológico, al que denomina "ágora", la arena pública (Nowotny 2011: 23). ${ }^{2}$ El resultado, en términos de utilidad, puede ser transferido para situaciones análogas. No obstante, no se trata de un saber de carácter universal, riguroso, coherente, como se supone que debe ser el saber científico. Este saber contextualizado es más bien "difuso,

Principia 16(2): 319-340 (2012). 
opaco, incoherente, centrífugo, híbrido" (op. cit.: 81; traducción mía, como todas las de este texto).

${ }^{3}$ La crítica es posible por la diseminación de la información pretendidamente científica por parte de los medios de comunicación (sobre todo, la internet), que exponen al mismo tiempo el carácter efímero y controvertido de muchos alegados descubrimientos.

${ }^{4} \mathrm{Y}$ "si el muy loado núcleo duro de la ciencia resulta estar vacío, dejémoslo estar vacio" (op.cit.: 233), concluyen los autores. Será substituido por "prácticas [epistémicas] locales", más o menos robustas y confiables según el contexto.

${ }^{5}$ Uno de los raros ejemplos es dado a propósito de la investigación genómica. Nowotny y sus colegas sostienen que "el núcleo epistemológico de la experimentación biológica está cambiando - de ser impulsado por hipótesis (hypothesis-driven), basado en los resultados de experimentos particulares, a ser basado en la producción sistemática y en vasta escala de datos, seguida por la modelización" (Nowotny 2010: 165).

${ }^{6}$ En este sentido, tanto la "consensibilidad" (la propiedad de las afirmaciones científicas de ser claramente entendidas y debatidas) como la "consensualidad" (la aptitud de las afirmaciones para suscitar eventuales consensos), deben ser preservadas, aunque de un modo diferente (op.cit.: 199). Las expresiones mencionadas, así como su significado, son originarias de John Ziman (v. Ziman 1995).

${ }^{7}$ Cabe advertir que, aunque se hable de esa transformación hace ya varias décadas, en la literatura filosófica, sociológica y en los Science Studies no hay consenso sobre sus características, su intensidad y hasta su existencia como una "ruptura epocal" (epochal break) (v. Nordmann et al. 2011).

${ }^{8}$ Los aspectos socialmente negativos o al menos cuestionables del Modo 2 de conocimiento no se encuentran enfatizados en Nowotny como en otros autores, como Echeverría (2003) y Ziman (2002). En The New Production of Knowledge (1994) los autores declaran expresamente que no evalúan la tendencia a pasar del Modo 1 al Modo 2 de investigación (id.: 3).

${ }^{9}$ Esas constataciones no excluyen dudas. ¿Hasta qué punto la ciencia actual, en su "Modo 2", es algo nuevo, y no algo ya presente, embrionariamente, en la ciencia tradicional? La ciencia académica, o "Modo 1" de investigación, ¿era (es aún) algo real, o constituye sólo una ilusión o una apelación ideológica? ¿Es posible una ciencia democrática orientada a (y por) el interés verdaderamente público? ¿La ciencia desinteresada, puede continuar a existir? ¿Tiene ella algún rol dentro de la ciencia democrática? Tratase de interrogantes que exigen investigaciones empíricas: históricas, sociológicas, económicas, politológicas. Y esos interrogantes, a su vez, presuponen o encierran cuestiones epistemológicas.

${ }^{10}$ Estoy entendiendo aquí la Epistemología (o Teoría del Conocimiento) como la disciplina filosófica que trata de la índole del conocimiento y de los criterios de validez teórica, sea del conocimiento en general, sea de una modalidad específica (en este caso, el conocimiento científico). Naturalmente, puede alegarse que el trabajo de Nowotny, aunque de pretensiones epistemológicas, no excede el ámbito de los Estudios Sociales de la Ciencia. Eso no lo exime de objeciones epistemológicas como las que aquí hago.

${ }^{11}$ Acentúo deliberadamente, en el pragmatismo, la relación creencia-acción, sin desconocer la dimensión coherentista que el pragmatismo incluye ("acuerdo final de los investigadores", para Peirce; "afirmabilidad garantizada", de Dewey).

12 En la medida en que la objetividad supone una realidad independiente, a la cual corresponderían las afirmaciones correctas, sirviendo de parámetro del conocimiento sensu stricto.

Principia 16(2): 319-340 (2012). 
13 Está en juego aquí, de una u otra forma, el tradicional enfrentamiento entre saber y poder. Ver Brown 2001: Who Rules in Science?

${ }^{14}$ Podría cuestionarse mi insistencia en la pregunta por el adecuado conocimiento de la realidad, pero ocurre que esa propiedad forma parte, precisamente, de la noción convencional de lo que sea ciencia. O mejor, de cierto modo la define.

${ }^{15}$ Eso vale tanto para los efectos secundarios de la utilización de un medicamento como para las consecuencias ambientales y sociales de la construcción de una represa, por ejemplo.

${ }^{16}$ Pueden valer como ejemplo, entre muchos, la "revolución verde" en la agricultura y la cura de enfermedades exclusivamente mediante remedios basados en la bioquímica, o en eventuales cirugías.

${ }^{17}$ La contextualización ya está ocurriendo, según Nowotny, aunque hay casos de contextualización "fuerte" (como en la investigación ambiental), "débil" (la Física, en particular) y "media" (mapeamiento del genoma humano) (Nowotny 2010, caps. 8, 9 y 10).

${ }^{18}$ De acuerdo con Nowotny, la expectativa de que la ciencia proporcionara la verdad (reformulable) sobre la realidad habría sido substitutiva de la más antigua confianza en que la religión o la tradición revelaran la verdad absoluta sobre el mundo y la vida. Esa expectativa ya habría cambiado al reemplazarse la verdad por la confiabilidad del saber científico, que sería cambiada en adelante por la robustez del mismo (op. cit.: 197).

${ }^{19}$ Nowotny se refiere siempre a las ciencias naturales, e a la incapacidad actual de las mismas para definir lo que sea la Naturaleza. Las ciencias sociales parecen haber estado siempre "contextualizadas" (op. cit.: 161). "La ciencia ya no puede fundamentar su autoridad cognoscitiva y social sobre la pretensión de tener un acceso único al orden del mundo natural (la comprensión del cual toma precedencia sobre la comprensión del mundo social, inherentemente más desordenada [messy] porque contaminada por intereses sociales, juicios de valor e ideologías" (id.: 230). Tratase, a mi ver, de una omisión lamentable. Es necesario saber cómo entienden estos autores la tarea (sea deficiente o deseada) de las ciencias sociales.

${ }^{20}$ Piénsese en la construcción de lugares de culto, o en las propuestas de solución para conflictos religiosos.

${ }^{21}$ ¿Por qué el ser humano procura conocer, aún cuando no parece precisar del conocimiento para fines prácticos? He ahí una pregunta difícil. Responder que lo hace porque es un animal curioso o porque es el "animal racional" puede ser visto como una falta de explicación.

${ }^{22}$ La posición de Ziman toca en un asunto que suscita cada vez más estudios: el del papel del científico como consultor (adviser) y mediador (broker), de quien no se espera ya que "diga la verdad al poder", sino que ofrezca un diagnóstico prudente, posibilitando decisiones políticas preferibles (v. esp. Pielke 2010 [2007]).

${ }^{23}$ Nowotny ilustra eso com la investigación para mapear el genoma humano realizada en el Reino Unido. El propósito de la investigación fue evolucionando en función de las diversas influencias que la investigación iba experimentando (Nowotny se apoya en un estudio sobre la relación ciencia-sociedad de Balmer [1996]). Siempre en la opinión de Nowotny, la "inteligencia artificial" sería un ejemplo de "objeto de Modo 2" que (aún) no resultó bien (Nowotny 2010: 147-51).

${ }^{24}$ Entiendo por constructivismo social radical aquel que insiste tanto en el papel de los intereses sociales en la producción del conocimiento que acaba por minimizar el papel de la realidad o la Naturaleza (entendida como entidad independiente). A pesar de protestos en contrario, autores como B. Latour (Science in Action, 1986) y Shapin \& Shaffer (Leviathan 
and the Air-Pump: Hobbes, Boyle and the Experimental Life, 1985) dan esa impresión al lector. ${ }^{25}$ Es claro que con la importante diferencia de que esa transformación del objeto es monopolizada por los científicos de la ciencia convencional, y resulta de diversos intereses en la ciencia "robusta".

${ }^{26}$ La ciencia objetiva u objetivadora no sería, según los críticos, capaz de captar los significados de los fenómenos humanos (Hermenéutica), produciría "falsa conciencia" (Neomarxismo), velaría el predominio "androcéntrico" (Feminismo).

${ }^{27}$ Nowotny cree que las normas mertonianas "son ahora en gran medida un anacronismo", pues en parte se volvieron obsoletas y en parte hay una distancia demasiado grande entre ellas y la ciencia efectiva (icomo si eso demostrase algo!) (id.: 2411). "Pero - agrega eso no significa que la ciencia se haya caído en un vacío normativo. Las normas actuales son improvisadas, diversas, volátiles y a veces hasta contradictorias" (ibíd.).

${ }^{28}$ De donde la importancia, en el epígrafe de esta sección, de la expresión "complementada". 29 "La ciencia, que se perdió en relación a la verdad, corre el riesgo de recibir de otros prescripciones acerca de lo que debe ser la verdad" (Beck 2010: 253, énfasis del autor).

Principia 16(2): 319-340 (2012). 